\title{
Dynamic response of an office building loaded by an explosion-generated air wave
}

\author{
D. Makovička ${ }^{1} \&$ D. Makovička Jr. ${ }^{2}$ \\ ${ }^{1}$ Czech Technical University in Prague, \\ Klokner Institute, Czech Republic \\ ${ }^{2}$ Static and Dynamic Consulting, Czech Republic
}

\begin{abstract}
This paper deals with determining the dynamic response of a standard office building to a nearby explosion due to a charge of explosives typically concealed in a motor vehicle. This particular case concerns the arrival of a truck with a terrorist charge of explosives initiated at some distance from the building. The structure selected for the dynamic analysis is a simple four-storey building with masonry walls and reinforced concrete floors, of a type widely used for administrative purposes. The response of the structure loaded by the pressure wave was computed by the methodology of equivalent static analysis, and a direct dynamic analysis was also made. The results of the two methods are used for a comparison of their information capacity with reference to the actual behaviour of the structure.

Keywords: building, explosion load, dynamic response, damage.
\end{abstract}

\section{Load due to the explosion effect}

The effect of the magnitude of the explosion load was determined for different magnitudes of the explosive charge and for different distances from the structure of the assessed building. In this case, the explosion of the charge can be considered as a surface explosion of a concentrated charge for all assessed variants of the source location.

Simplification of the charge of explosives in a truck to a concentrated charge is justified, since even in the case of a relatively large quantity of explosives (of the order of hundreds of kilograms) the whole charge will explode simultaneously at the moment of initiation. 

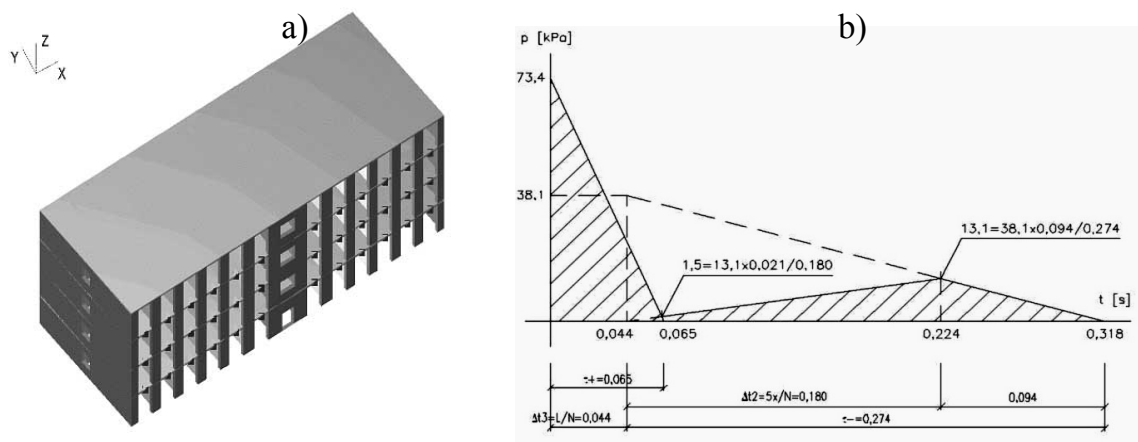

Figure 1: $\quad$ Building structure (a) and Time function of overpressure (b).

The empiric formulae for determining the history of overpressure and underpressure consider the explosion of a charge up to $20 \mathrm{~m}$ above ground level as a surface explosion. The explosion generates a pressure wave, the dominant effect of which on a standard building structure manifests itself, as a rule, by the flexure of its members or their displacement along pre-collapse cracks, or by a displacement due to the failure of the supports, anchorage suspensions and fastening components of individual structural members or interior equipment (such as heavy pieces of furniture).

The parameters of the impact wave generated by the explosion were estimated by the following empiric formulae:

$$
C_{\mathrm{w}}=W \cdot \frac{Q_{\mathrm{sm}}}{Q_{\mathrm{TNT}}},
$$

where $C_{\mathrm{w}}$ is equivalent charge mass $[\mathrm{kg}$ TNT]; $W$ is mass of actual explosive capable of detonation [kg]; $Q_{\mathrm{sm}}$ is specific heat of the used explosive $[\mathrm{kJ} / \mathrm{kg}]$, and $Q_{\mathrm{TNT}}=4200 \mathrm{~kJ} / \mathrm{kg}$ is specific heat of the TNT explosive.

Peak overpressure and underpressure intensities at the front of the impact air wave and their period:

$$
\begin{gathered}
p_{+}=\frac{1.07}{\bar{R}^{3}}-0,1 \text { for } \bar{R} \leq 1, \\
p_{+}=\frac{0.0932}{\bar{R}}+\frac{0.383}{\bar{R}^{2}}+\frac{1.275}{\bar{R}^{3}} \text { for } 1 \leq \bar{R} \leq 15, \\
p_{-}=\frac{0.035}{\bar{R}}, \\
\tau_{+}=1.6 \cdot 10^{-3} \cdot \sqrt[6]{C_{\mathrm{w}}} \cdot \sqrt{R} \\
\tau_{-}=1.6 \cdot 10^{-2} \cdot \sqrt[3]{C_{\mathrm{w}}}
\end{gathered}
$$

where $p_{+}$is maximum overpressure of the incident wave front [MPa]; $p_{-}$is maximum underpressure with reference to atmospheric level [MPa]; $\bar{R}$ is 
reduced distance of the front of the building from the epicentre of the explosion $\left[\mathrm{m} / \mathrm{kg}^{1 / 3}\right] ; \tau_{+}$is duration of the overpressure phase $[\mathrm{s}]$, and $\tau_{-}$is duration of the underpressure phase [s].

Wave front velocity and velocity thrust [1]:

$$
\begin{gathered}
N=340 \cdot \sqrt{1+8.3 \cdot p_{+}}, \\
p_{+\mathrm{n}}=\frac{2.5 \cdot p_{+}^{2}}{p_{+}+0.72},
\end{gathered}
$$

where $N$ is wave front velocity $[\mathrm{m} / \mathrm{s}]\left(p_{+}\right.$is in $\left.[\mathrm{MPa}]\right)$ and $p_{+\mathrm{n}}$ is velocity thrust $[\mathrm{MPa}] ; p_{+}$is overpressure at the front of the incident impact air wave in [MPa].

The normal pressure wave incidence on a solid obstacle generates a reflected

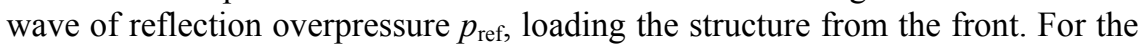
given distance $R$ the overpressure in the reflected wave, consequently, corresponds to twice to eight times the overpressure of the incident wave:

$$
p_{\text {ref }}=2 \cdot p_{+}+\frac{6 \cdot p_{+}^{2}}{p_{+}+0.72},
$$

where $p_{\text {ref }}$ is overpressure in the reflected wave $[\mathrm{MPa}]$ and $p_{+}$is overpressure at the incident impact air wave front [MPa].

In the case of oblique incidence, the effects of the impact wave on the obstacle are lower, depending on the parameters of the propagating wave, the angle of incidence, the parameters of the obstacle, etc.

The analyzed building was loaded by the following pressure wave under almost perpendicular incidence:

$p_{+}=34.9 \mathrm{kPa} \ldots$ overpressure at the incident wave front,

$p_{\text {ref }}=73.4 \mathrm{kPa} \ldots$ overpressure in the reflected wave,

$\tau_{+}=0.065 \mathrm{~s} \ldots$ overpressure duration.

The dynamic load generated by the explosion corresponds with the reflected overpressure of the incident impact wave. The building is $44 \mathrm{~m}$ in length, the explosion is considered at a distance of some $100 \mathrm{~m}$ symmetrical to the axis of its central part (passing through the entrance door). The lateral reflected overpressure represents a continuous and practically regularly distributed load (angle of incidence within the limits of $77^{\circ}$ and $90^{\circ}$ ).

Let us assume that the pressure does not change with elevation above ground level (which is the next simplification; in reality, the change of pressure in the vertical direction is also continuous and variable within relatively small limits).

For front wall loading, we assume that the load is applied instantaneously; this simplification neglects the phase shift of the beginning of load application to individual points of the structure.

Finally, let us assume that the explosion load is applied only in the direction of the normal to the front wall (with regard to the load magnitude, the lateral effect of the impact wave on the structure; in the case of oblique reflection nearing $90^{\circ}$, the lateral load component acting in the central plane of the wall is also neglected). 


\section{The building structure and the theoretical model}

Apart from the ground floor at \pm 0.00 level, the assessed building has three other above-ground storeys and a roof slab. The clear storey height is $3000 \mathrm{~mm}$, and the total thickness of the floor structures is $250 \mathrm{~mm}$. The floors are RC plates $200 \mathrm{~mm}$ in thickness, with $50 \mathrm{~mm}$ flooring.

The masonry of the walls consists of Keratherm ceramic blocks; the outside walls are $450 \mathrm{~mm}$, the corridor walls $300 \mathrm{~mm}$, and the partitions $200 \mathrm{~mm}$ in thickness. The load-bearing structure system consists of the outside walls with two longitudinal corridor walls and floor plates. The building is founded on RC foundation strips, in which the vertical masonry and pillars are constrained.

The theoretical model of the structure is illustrated in fig. 1. The partitions $200 \mathrm{~mm}$ and less in thickness are usually considered as non-load-bearing structures in static and dynamic analyses. In our case, however, we have included them in the computation model to make it as near as possible to reality.
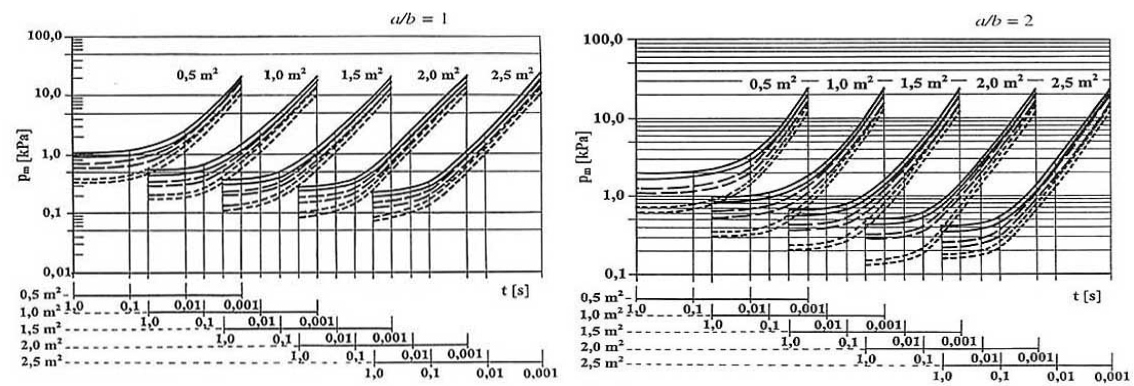

Figure 2: $\quad$ Bunch graph for the computation of window glazing breaking in dependence on overpressure $\mathrm{p}_{\mathrm{m}}$ of the loading impact wave, overpressure duration $\mathrm{t}$, glazing area A, glass thickness $(3 \mathrm{~mm}-$ dotted line, $4 \mathrm{~mm}$ - dash-and-dot line, $5 \mathrm{~mm}$ - solid line) and window glass age (pairs of lines of the same type define new glass and ten-year old glass); ratio of window glass dimensions a) $\mathrm{a} / \mathrm{b}=1, \mathrm{~b}) \mathrm{a} / \mathrm{b}=2$

\subsection{Natural vibration analysis}

In order to determine the response of the building to explosion effects it is necessary to determine the dominant natural frequencies corresponding to the fundamental flexural vibrations of the building as a whole, and where possible the structural parts with natural periods approaching the period of overpressure wave impact.

The fundamental flexural frequencies of the building as a whole correspond with the first three natural frequencies in the vicinity of $2 \mathrm{~Hz}$ with dominant displacements in the longitudinal direction $x$, or in the transverse direction $y$, and/or in torsion of the whole structure about the central axis $z$ of the building, 
which are most significant for the structure with reference to impact wave load characteristics. These frequencies cause flexure of the columns and peripheral and corridor walls in the dominant (horizontal) direction, while the floor plates and thin partitions remain without significant deformation.

The natural frequencies of the floor vibrations are manifested by the flexure of the floor plates in direction $z$ simultaneously with transverse flexure of the thin partitions at frequencies from $4.78 \mathrm{~Hz}$ upwards. Simultaneously with the flexure of the floor plates, the axial vibration of the brick masonry columns and load-bearing walls in the vertical direction $z$ also takes place in the appropriate part of the structure.
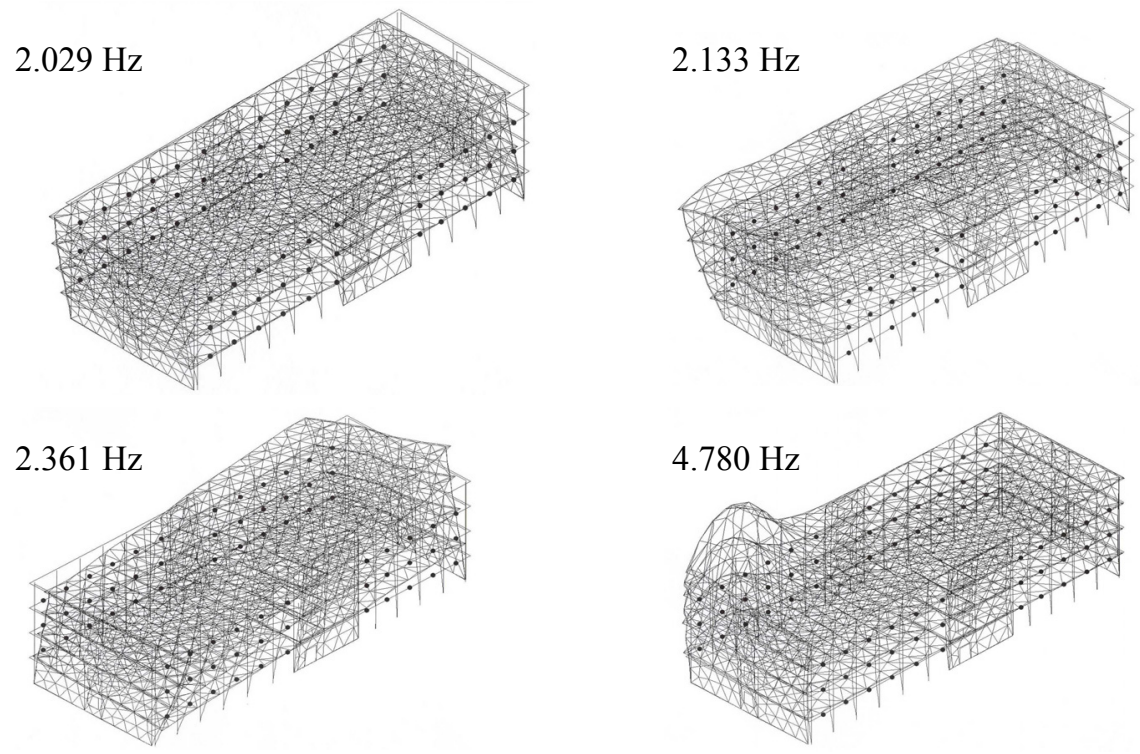

Figure 3: The lowest natural frequency of building vibrations.

\subsection{Forced vibration analysis}

\subsubsection{Equivalent static analysis}

In order to simplify the dynamic behaviour of the structure and its load to the equivalent static behaviour, only the maximum magnitude of the reflection overpressure $p_{\text {ref }}$ (dynamic load level) and its duration $\tau_{+}$are significant for determining the magnitude of the steady state factor $\delta$.

The steady state factor $\delta=0.6$ for overpressure duration $\tau_{+}=0.065 \mathrm{~s}$ and the dominant natural frequency (of the transverse vibrations) of $2.133 \mathrm{~Hz}$ has been determined in dependence on the product $\tau_{+} \cdot f_{2}=0.065 \cdot 2.133=0.14$ and for the triangular excitation history, so that the equivalent static horizontal load applied to the front wall is $p_{\mathrm{ekv}}=p_{\mathrm{ref}} \cdot \delta=0.44 \mathrm{kPa}$. 
In the initial phase of load application to the structure up to the maximum dynamic load level, the window structures (until the moment of their destruction) also transfer the impact wave load to the brickwork pillars and the walls between them; therefore the load width of the pillars and walls with openings was converted to the full front façade area. The moment of window destruction can be estimated on the basis of the window parameters from the bunch graphs in fig. 2 [2]. The windows are destroyed when the pressure level in the incident wave amounts to approximately $1.3 \mathrm{kPa}$, which corresponds to the load impact on the wall (reflection overpressure) on the level of approximately $2.7 \mathrm{kPa}$. As the load $p_{\mathrm{m}}=2.7 \mathrm{kPa}$ is much smaller than $73.4 \mathrm{kPa}$, the windows in the whole front wall will break and the pressure effect will be transferred to the internal walls inside the building.

The equivalent static analysis corresponds to conversion of the dynamic load to substitute static load, so that the information on the moment of maximum response can merely be estimated according to the dominant natural frequency of the building. This type of analysis is made only for the dominant frequency, whether of the load or of the natural frequency of the building, so that information on the influence of the higher harmonic components can also only be estimated, or possibly determined by repeated equivalent analysis. In this particular case, the analysis was made only for the second natural frequency $2.133 \mathrm{~Hz}$ and the triangular history of the load produced by the impact wave of $\tau_{+}$duration. The magnitude of the displacements of the whole structure and their mutual ratio is illustrated by the deformed shape of the building under this load, shown in fig. 3.

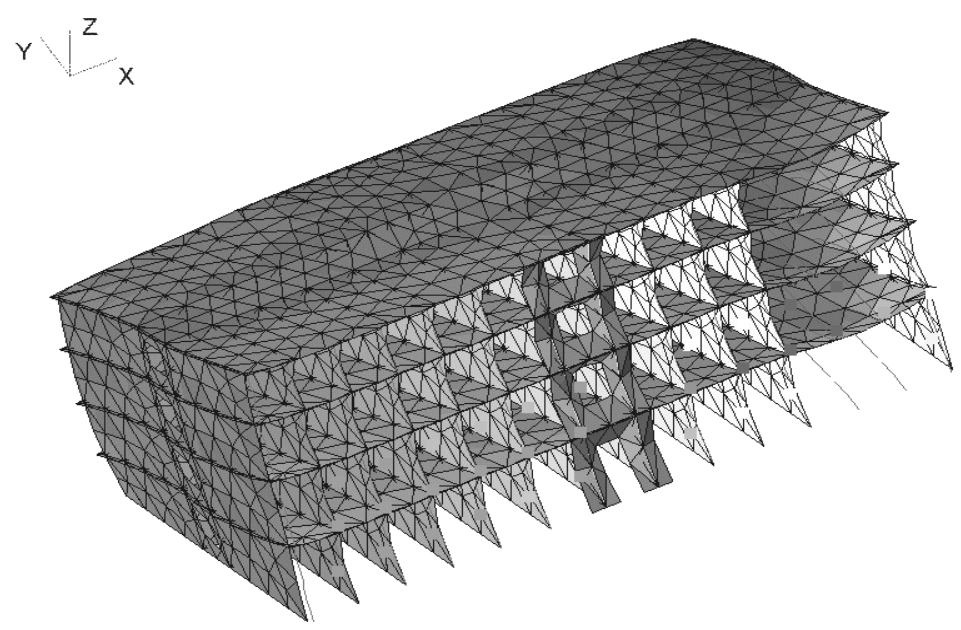

Figure 4: Building deformation under explosion load, determined by equivalent static analysis. 


\subsubsection{Detailed 3D dynamic analysis}

The analysis of the response of the 3D model of the structure was performed for the actual history of excitation. The incident wave first impacts the front wall of the building. The load of this wall corresponds with the reflection overpressure $p_{\text {ref. }}$ Immediately after impact of the pressure wave on the obstacle, the roundflow starts. The influence of the impact wave disappears after the time $\Delta t_{1}=0.108 \mathrm{~s}$. The excitation history, computed according to the methodology given in [1], is shown in fig. 4 .

This application of overpressure to the front wall disappears in time $\tau_{+}$. This means that during the whole time $\tau_{+}$(the time of overpressure action on the front wall) the reflection overpressure $p_{\text {ref }}$ loads the front wall structure. From the time

$$
\Delta t_{3}=L / N=17.2 / 386.2=0.044 \mathrm{~s}
$$

the overpressure starts acting on the rear wall of the building through vortices generating suction at the rear wall. This effect produces a pressure increase until the time

$$
\Delta t_{2}=5 \cdot X / N=5 \cdot 13.9 / 386.2=0.180 \mathrm{~s},
$$

where $N$ is velocity of the front of the propagating wave, $X$ is the smaller of the dimensions of the bypassed building $B / 2$ or $H, B=44,0 \mathrm{~m}$ is building width (perpendicular to the direction of impact wave propagation), $H=13.9 \mathrm{~m}$ is building height above ground level and $L=17.2 \mathrm{~m}$ is building depth (in the direction of wave propagation).

The theoretical peak value of overpressure applied to the rear wall of the building at the time $\Delta t_{3}$ is $p_{+}+k_{\mathrm{p}} \cdot \mathrm{p}_{\mathrm{n}_{\mathrm{n}}}=34.9+0.8 \cdot 4.0=38.1 \mathrm{kPa}$.

The actual maximum of overpressure applied to the rear wall of the building takes place at the time $\Delta t_{3}+\Delta t_{2}=0.224 \mathrm{~s}$, achieving the magnitude of $13.1 \mathrm{kPa}$. The application of overpressure to the rear wall of the building disappears completely at the time $\Delta t_{3}+\tau_{-}=0.318 \mathrm{~s}$.

The theoretical peak value of overpressure applied to the rear wall of the building at the time $\Delta t_{3}$ is $p_{+}+k_{\mathrm{p}} \cdot \mathrm{p}_{+\mathrm{n}}=34.9+0.8 \cdot 4.0=38.1 \mathrm{kPa}$.

The actual maximum of overpressure applied to the rear wall of the building takes place at the time $\Delta t_{3}+\Delta t_{2}=0.224 \mathrm{~s}$, achieving the magnitude of $13.1 \mathrm{kPa}$. The application of overpressure to the rear wall of the building disappears completely at the time $\Delta t_{3}+\tau_{-}=0.318 \mathrm{~s}$.

The damping is introduced to the direct dynamic non-harmonic analysis by means of the coefficient $\alpha$ applied to the matrix of system mass and the coefficient $\beta$ applied to the stiffness matrix (Rayleigh damping). This relative damping was considered with the value of $5 \%$, corresponding to the flexural vibrations at the lowest natural frequencies, and the coefficients $\alpha=0.670$ and $\beta=0.00373$.

The maximum displacement of the structure under the impact load in the load direction occurs approximately $0.15 \mathrm{~s}$ after the impact of the wave on the structure. The maximum displacements of the structure against the direction of load application take place at $0.40 \mathrm{~s}$. The displacement history at the selected 
point (roof slab intersection with front wall - left hand corner) is shown in fig. 5 . The maximum vibration displacements achieved are: at the time of $0.15 \mathrm{~s} \mathrm{\ldots} 41.0 \mathrm{~mm}$ in the load impact direction, at the time of $0.40 \mathrm{~s} \ldots 22.6 \mathrm{~mm}$ against the load impact direction.

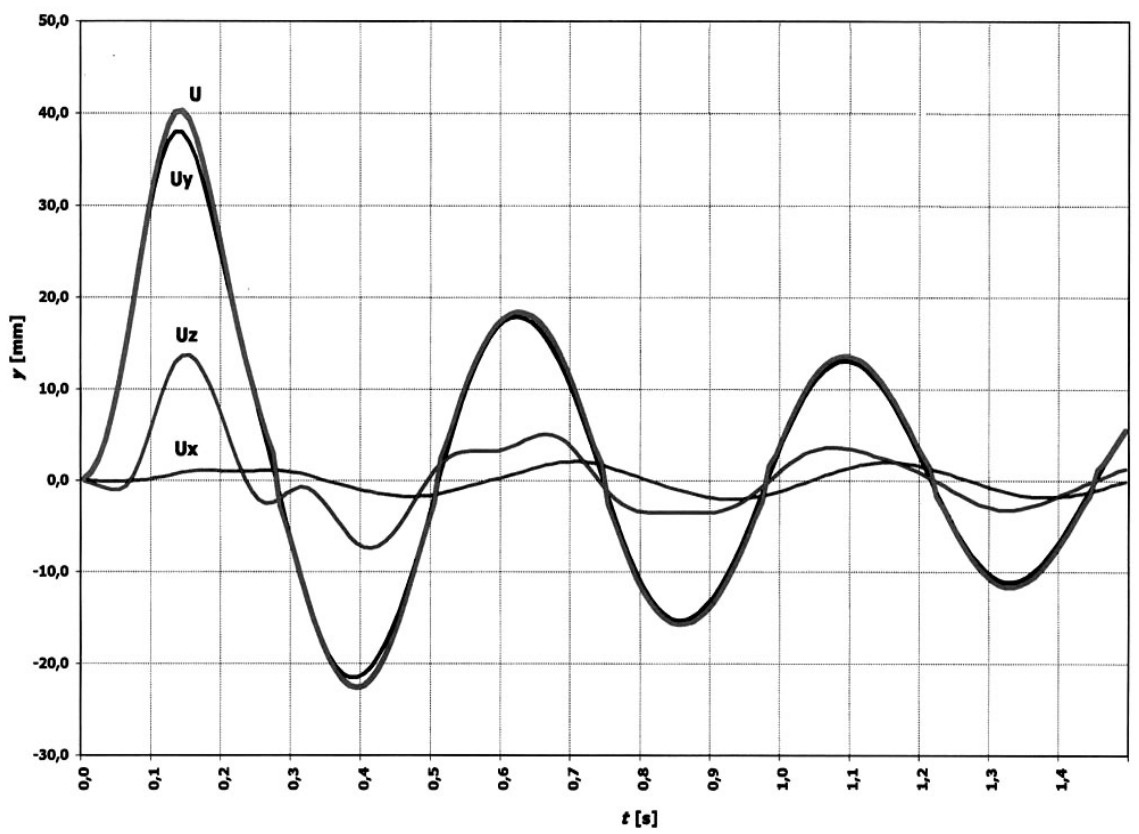

Figure 5: Amplitude history at a selected point (intersection of roof slab with front wall - left hand corner) determined by 3D analysis.
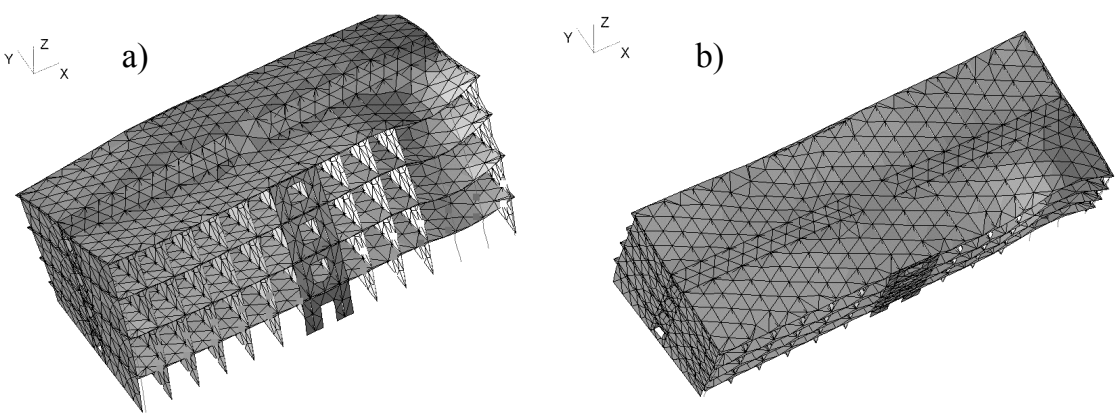

Figure 6: Limit shape of building deformation determined by 3D analysis a) in the direction of, and b), against the direction of the pressure wave effect. 
In these transitional vibrations the building structure vibrates several times at approximately its natural frequency of $2.13 \mathrm{~Hz}$, which is the dominant frequency component of the response for the direction of the impact wave effect. Further natural frequencies of the building are superposed on this dominant frequency.

For $450 \mathrm{~mm}$ outside walls, the maximum stress amplitudes at the time of $0.15 \mathrm{~s}$ are as much as $+1.0 \mathrm{MPa}$ in the middle plane of the masonry in the lowest storeys at the contact with the front wall; for $200 \mathrm{~mm}$ partition masonry, the maximum stress amplitudes are as much as $+0.85 \mathrm{MPa}$ tensile stress in the middle plane of the partition masonry in the lowest three storeys at the contact with the front wall.

Due to the load applied to the structure by the explosion all glazed surfaces, including glazed internal doors, will be broken and the window and door frames will be torn out throughout the building. This damage is due to the fact that the reflection overpressure as well as the overpressure at the rear wall of the building and the lateral overpressure greatly exceed the overpressure magnitude at which this damage takes place.

The computed dynamic stresses make it obvious that the tensile stress state of the masonry due to the explosion effects in the linear analysis attains values of about $1 \mathrm{MPa}$ [3]. From the superposition of the stress state due to long-term dead loads on the stress state due to dynamic loads, it follows that the structure should be able to transfer tensions of the order of 0.3 to $0.5 \mathrm{MPa}[4,5]$. According to the standards, the tensile strength of masonry is 0.02 to $0.04 \mathrm{MPa}$ [6], depending on the direction of tensile stress application. As the masonry strength is of a lower order than the stress state of the masonry due to the explosion, cracks originate in the masonry even before the maximum response magnitude has been attained. This means, of course, that the cracked masonry structure will be affected both by the exposition overpressure from outside and by the impact wave which has penetrated into the building from inside. The combination of the damaged structure with the pressure effects will result in the collapse of at least the two lowest storeys, at least in the front part of the building as far as the corridor. As a result of this collapse the whole structure will become unstable, and this will probably cause the collapse of the floors and the breakdown of the whole structure.

\section{Conclusions}

The equivalent static analysis simplifies the theoretical model of the structure to the response of a system with one degree of freedom referred only to the dominant vibration frequency. Direct dynamic analysis of forced vibrations takes into account the tuning of the building structure in the whole spectrum of natural frequencies. This $3 \mathrm{D}$ analysis results in a more accurate determination of the vibration amplitudes and internal forces in the individual structural members. Although the magnitudes of the maximum amplitudes in the two cases are very similar, the vibration mode of the whole building structure is different; the equivalent static analysis takes into account only one dominant natural mode, 
while in the dynamic analysis higher or lower natural modes are also superposed on this dominant mode.

These fundamental simplifications also generate further differences in the results of the two methods. In comparison with the dynamic analysis, the equivalent static analysis lacks the phase characteristics between the individual frequency components of the response (equivalent static analysis takes into account one dominant frequency only) and, naturally, also the response history. Another significant simplification in the equivalent static analysis lies in the fact that the dynamic load is considered with one value only (maximum overpressure, as a rule), while dynamic analysis introduction of any history of load application. As a consequence of this approach, dynamic analysis makes it possible to respect not only the maximum magnitude of the load, but also its whole history, and possibly also the vibrations of the structure after the end of load application.

On the other hand, the advantage of the equivalent static analysis is that it is less exacting in terms of computer time, although it is necessary to set up the theoretical model of the structure for determining the dominant natural vibration, unless we make further significant simplifications of the model of the structure for the equivalent static analysis. In such a case the agreement of the maximum amplitude between the two methods will be poorer.

\section{Acknowledgement}

This research was supported under GAČR No 103/03/0082 "Nonlinear response of structures under extraordinary loads and man-induced actions", for which the authors would like to express their thanks the Agency.

\section{References}

[1] Henrych, J.: The dynamics of explosion and its use, Academia, Prague 1979.

[2] Makovička, D.: Shock wave load of window glass plate structure and hypothesis of its failure, SUSI'98, Comp. Mechanics Publications, Southampton, 1998, pp. 43-52.

[3] Makovička, D., Král, J., Makovička, D.: Dynamic response of masonry partition structure to inside explosion effect, Building Research Journal Vol. 51, 2003, No 1-2, pp. 83-96.

[4] Makovička, D., Makovička, D.: Explosive failuring of masonry structure, In: Vejvoda, S.: Transactions of $17^{\text {th }}$ International Conference on SMiRT, Prague, University of Technology in Brno, 2003, pp. $236+8$ pp. on CD.

[5] Makovička, D., Makovička, D.: Failure of masonry under explosion effect, In: Jones, N., Brebbia, C.A.: Structures Under Shock and Impact VIII, WIT Press, Southampton, 2004, pp. 475-484.

[6] Eurocode 6: Design of masonry structures - Part 1-1: Common rules for reinforced und unreinforced masonry structures. prEn 19961-1, October 2001. 